\title{
PENGEMBANGAN DESA WISATA DAN PEMBANGUNAN PARIWISATA BERKELANJUTAN DESA WATUAJI
}

\author{
1) Tristan Alfian, ${ }^{2)}$ Yayan Adi Saputro, ${ }^{3)}$ Gun Sudiryanto \\ 1),2),3) Fakultas Sains dan Teknologi, Universitas Islam Nahdlatul Ulama Jepara \\ J1. Taman Siswa (Pekeng) Tahunan Jepara \\ E-mail : Alviantristan@gmail.com
}

\begin{abstract}
ABSTRAK
Potensi pariwisata Desa Watuaji memiliki bebatuan yang unik diantaranya ada watu gebyok, watu lawang, watu soko, watu tumpuk dan watu tatal. Hal ini berpadu dengan pemandangan alam yang sangat memukau karena berada di lereng gunung muria bagian utara, dengan rata-rata pekerjaan penduduknya bertani dan berkebun, Watuaji memiliki hamparan sawah yang membentang dan juga perkebunan apokat dan kopi yang luas. Keadaan alam yang seperti ini sangat cocok dijadikan wisata alam, dan destinasi desa wisata. Di desa watuaji sudah terbentuk POKDARWIS pada tahun 2019 mengalami beberapa kendala diataranya dana desa yang belum cair untuk penerusan pembangunan, akses jalan menuju lokasi masih susah, serta belum adanya master plan. Untuk itu kami tim KKN menawarkan solusi berupa pembuatan master plan dan tata ruang taman di area lokasi watu tumpuk, sehingga bisa menjadi alternative pembangunan wisata jangka pendek, untuk selanjutkan pembangunan jangka panjang di area watu gebyok. Metode pelaksaan dilakukan 4 tahap yaitu melakukan analisis dengan mitra, melakukan kerja sama dengan mitra, pengerjaan rencana dan pembangunan teman. Target capaiaan KKN ini adalah untuk mewujutkan desa wisata di desa Watuaji, sehingga dapat meningkatkan pendapatan kelompok ataupun masyarakat sekitar dalam rangka mempercepat pemulihan ekonomi dan social.
\end{abstract}

Kata Kunci: Pariwisata, desa, master plan.

\begin{abstract}
The tourism potential of Watuaji Village has unique rocks including watu gebyok, watu lawang, watu soko, watu stack and watu tatal. This is combined with a very stunning natural scenery because it is located on the northern slopes of Mount Muria, with the average occupation of the population being farming and gardening, Watuaji has views of stretches of rice fields as well as extensive avocado and coffee plantations. Natural conditions like this are very suitable for nature tourism and tourist villages. In Watuaji Village, POKDARWIS was formed in 2019 experiencing several problems with village funds that have not been disbursed for continuing development, road access to the location is still difficult, and there is no master plan. For this reason, our KKN team offers a solution in the form of making a master plan and garden layout in the Watu Stack area, so that it can be an alternative for short-term development, to continue long-term development in the Watu Gebyok area. The implementation method is carried out in 4 stages, namely analyzing with partners, collaborating with partners, working on plans and building friends. The target of achieving this KKN is to realize a tourist village in Watuaji village, so that it can increase the income of groups or surrounding communities in the context of economic and social recovery.
\end{abstract}

Keyword: Tourism, village, master plan

\section{PENDAHULUAN}

Reformasi menjadi tonggak sejarah bagi Indonesia yang mendorong perubahan tata pemerintahan di negeri ini. Perubahan system pemerintah dari sentralisasi kea rah desentralisasi menjadi factor penentu. Pemerintah pusat memberikan otonomi daerah agar dapat mengatur tata kelola untuk menjadi lebih baik sesuai dengan aspirasi masyarakat yang ada, hal ini selaras dengan peraturan perundang-undangan nomor 32 tahun 2004. peraturan perundang-undangan terkait mampu mengakomodir aspirasi masyarakat dalam mengembangkan sector pariwisata sesuai dengan potensi yang ada dengan memperhatikan jumlah peningkatan pendapatan daerah. Kabupaten Jepara provinsi Jawa Tengah saat ini sedang berbenah dalam rangka meningkatkan pendapatan asli daerah (PAD) melalui pengembangan wisata yang ada baik dari wisata alam, 
budaya, sejarah dan religi. Desa wisata kini menjadi program pemerintah daerah untuk meningkatkan pendapatan desa lewat sektor pariwisata. Maka dari itu, pengembangan wisata yang ada di seluruh kabupaten Jepara hendaknya menjadi perhatian khusus bagi pemerintah untuk mengembangkan dan melestarikan wisata tersebut sehingga menjadi sumber pendapatan dana desa.

Banyak sekali wisata yang ada di seluruh kabupatan Jepara, salah satunya wisata yang ada di desa watuaji kecamatan keling yang perlu menjadi perhatian khusus dan program desa untuk mengembangkan desa wisata sekaligus pembangunan pariwisata berkelanjutan yang ada di desa watuaji. Sebenarnya banyak sekali potensi wisata yang ada di desa watuaji, hanya saja potensi tersebut belum diketahui oleh khalayak umum. Desa Watuaji adalah salah satu desa yang terletak di kecamatan Keling Kabupaten Jepara. Wisata desa watuaji yang terletak dilereng utara gunung muria, berjarak kurang lebih $30 \mathrm{KM}$ dari pusat kota Jepara. Diantara potensi wisata yang ada didesa watuaji menurut kepala desa watuaji adalah Watu Tatal, Watu Gebyok, Watu Soko, dan Watu tumpuk yang semuanya merupakan potensi alam yang sejak dulu tidak terurus. Keberagaman potensi tersebut menjadi kekuatan dan peluang untuk pengembangan desa wisata Watuaji tersebut. Kemampuan mengelola peluang dan kekuatan tersebut tidak direncanakan dengan baik, hal ini justru akan menjadi tantangan dan kelemahan. Potensi-potensi wisata yang belum begitu dikenal dan belum terangkat ke permukaan perlu untuk digali dan diinventarisasi untuk dikelola dan dirancang sebagai sebuah daya tarik wisata untuk dapat menarik wisatawan datang berkunjung ke desa Watuaji. Hal ini, memerlukan suatu pengetahuan dan pemahaman yang baik dan sinergi antara beberapa pihak terkait atau stakeholder dalam proses pembuatannya, dimana masyarakat lokal yang lebih banyak berperan karena mereka yang mengetahui secara detail tentang potensi-potensi wisata yang mereka miliki[1]. Potensi besar tanpa didukung oleh pengelolaan yang baik dengan SDM yang kurang memadai, apalagi menekankan pengembangan desa wisata yang berbasis masyarakat dan berkelanjutan, maka akan menjadi sangat penting sebuah Badan yang jelas yang dibentuk dari masyarakat untuk mengelola desa wisata di Watuaji.

Alasan pengabdi memilih mitra tersebut dalam kegiatan ini adalah untuk membantu mengembangkan dan mempromosikan wisata yang belum terkenal padahal letak lokasi wisata yang ada di Watuaji ini pada jalur wisatawan menuju arah Tempur. Sehingga sangat disayangkan sekali desa ini hanya dilewatkan begitu saja. Untuk itu, tim pengabdi berniat membantu membangun wisata berkelanjutan di desa Watuaji dengan memanfaatkan potensi wisata bebatuan yang belum dikenal oleh khalayak umum sehingga kelak dapat dijadikan wisatawan untuk berkunjung dan melihat kondisi suasana di pegunungan yang asri dan sejuk.

Berdasarkan pemikiran di atas, tim pengabdi memandang bahwa sebenarnya desa Watuaji ini memiliki potensi wisata yang menarik dan perlu dilestarikan dengan adanya peninggalan batu-batu prasejarah yang ada di desa Watuaji tersebut. Untuk itu, tim pengabdi bermaksud menyelenggarakan pengabdian kepada masyarakat untuk mengembangkan desa wisata dan pembangunan pariwisata secara berkelanjutan. Adapun mitra yang dipilih dalam kegiatan ini adalah membuat master plan di watu gebyok dan membuat taman di sekitar watu tumpuk. Karena memang pada dasarnya banyak sekali macam-macam peninggalan bebatuan yang ada di desa watuaji sehingga tim pengabdi berminat untuk mengembangkan batu-batuan yang ada di 
sekitar desa Watuaji tersebut untuk dijadikan sebagai lokasi wisata yang ada di kecamatan Keling.

\section{Pariwisata}

Pariwisata merupakan sesuatu kegiatan dari yang dicoba oleh turis ke sesuatu tempat tujuan wisata di luar keseharian serta area tempat tinggal buat melaksanakan persinggahan sedangkan waktu dari tempat tinggal, yang didorong sebagian keperluan tanpa bermaksud buat mencari nafkah serta tetapi didasarkan atas kebutuhan buat memperoleh kesenangan, serta diiringi buat menikmati bermacam hiburan yang bisa membebaskan letih serta menciptakan sesuatu travel experience serta hospitality service[2][3].

Dalam aktivitas pariwisata komponen- komponen pariwisata hendak silih terpaut dalm pendukung pengembangan sesuatu kawasan. Komponen pariwisata dipecah atas 2 aspek, ialah komponen penawaran( supply) dari pariwisata serta komponen permintaan( demand) dari pariwisata. Kesediaan pariwisata mencakup semua yang ada didaeran dan ditawarkan kepada turis meliputi transportasi, akomodasi, infrastruktur, dan sarana pendukung lainnya. Sebaliknya permintaan ataupun demand pariwisata merupakan seluruh suatu yang berhubungan dalam proses permintaan pariwisata ialah wisatawan serta warga.

\section{Desa Wisata}

Desa wisata merupakan suatu kawasan pedesaan yang mempunyai sebagian ciri spesial buat jadi wilayah tujuan wisata. Di daerah ini, penduduk yang menempati masih mempunyai tradisi serta budaya yang belum tersentuh dan masih asli. Tidak hanya itu, sebagian aspek pendukung semacam santapan khas, sistem pertanian serta sistem sosial ikut memberi warna suatu area desa wisata. Di luar faktor- faktor tersebut, alam serta area yang masih asli serta terpelihara ialah salah satu aspek terutama dari suatu kawasan tujuan wisata[4].

Desa wisata merupakan sesuatu daerah pedesaan yang memberikan kesan originalitas yang meliputi keaslian segi sosial budaya, arsitektur adat-istiadat, keseharian, struktur tata ruang desa yang diwujudkan dalam sesuatu sesuatu wujud integrasi bagian pariwisata yang meliputi atraksi, akomodasi serta sarana pendukung lainnya[3].

Sejalan dengan dinamika, gerak pertumbuhan pariwisata memasuki dalam bermacam terminologi semacam, sustainable tourism development, rural tourism, ecotourism, ialah pendekatan pengembangan kepariwisataan yang berupaya buat menjamin supaya wisata bisa dilaksanakan di wilayah tujuan wisata dan itu bukan suatu wilayah perkotaan. Adapun salah satu pengembangan wisata dengan jalan lain adalah desa wisata buat pembangunan pedesaan yang berkepanjangan dalam bidang pariwisata.

\section{Master Plan Desa Wisata}

Masterplan merupakan sebuah rencana induk yang didalamnya berisi dokumen perencanaan tata letak dan tata ruang yang mengatur seluruh fasilitas umum, fasilitas penunjang dan sosial sesuai dengan fungsi dan tujuan pengembangan. Secara umum masterplan telah mencakup seluruh tujuan kegiatan dengan dilengkapi rencana sistem jaringan transportasi dan sarana prasarana penunjang[5]. Rencana yang dibuat dapat berbentu dan atau tertuang dikertas dengan skala tertentu atau juga dapat berbentuk file digital dengan ukuran yang jelas. [6]. 
Secara umum masterplan merupakan rencana skala besar yang bersifat menyeluruh mencakup semua fasilitas fisik yang berupa infrastruktur bangunan, alur transportasi, tata ruang aktivitas, dengan jangka waktu tertentu, serta terdapat jumlah pendanaan yang akan ditimbulkan, hingga semua pihak yang terlibat[6]. Adapun tujuan utama masterplan adalah untuk memberikan kemudahan dalam proses pembangunan. Hal ini juga didasarkan pada pada visi pembangunan dan pengembangan kawasan. Hal ini diharapkan dapat memberikan output kesejahteraan, baik secara ekonomi, social dan budaya[7]. Selain itu, master plan juga memiliki tujuan untuk memfasilitasi kerangka kerja kedepan atau pengembangan kawasan di masa yang akan datang. Hal ini merupakan rencana strategis yang didalamnya berisi lokasi, skala dan jenis perkembangan akan terjadi di daerah tertentu.

\section{METODE PELAKSANAAN}

Kegiatan pengabdian ini dilakukan di Desa Watuaji Kecamatan Keling Kabupaten Jepara. Rangkaian kegiatan yang dilakukan adalah sebagai berikut :

1. Analisis Situasi dan potensi

Analisis situasi dilakukan dengan metode wawancara dan observasi lokasi, dua kegiatan ini dilakukan untuk mengetahui kondisi mutakhir dari mitra program. Dalam hal ini tim melakukan wawancara dengan pokdarwis desa watuaji juga dengan petinggi desa watuaji, juga melakukan observasi lapangan dengan melihat potensi alam didesa watuaji untuk nantinya dikembangkan menjadi desa wisata. Dari hasil analisis situasi dan melihat potensi yang ada desa watuaji sudah mendapatkan SK Desa Wisata dari dinas pariwisata kabupaten jepara. Sehingga Potensi alam yang dimiliki desa watuaji sangat berpotensi dijadikan wisata. Pokdarwis desa watuaji dan petinggi desa watuaji sangat antusias untuk mengembangkan wisata diwatuaji, tetapi belum ada master plan untuk pembangunan wisata diwatu gebyok. Oleh karena itu, progja kkn berbasis kemitraan dimaksudkan untuk menjembatani pokdarwis dan petinggi desa watuaji mewujudkan desa watuaji menjadi desa wisata.

2. Penjajakan kerjasama

Dalam hal ini, tim pengabdian melakukan koordinasi terlebih dahulu dengan petinggi desa watuaji, yakni bapak juanidi, S.Sos. dan ketua pokdarwis desa watuaji, yakni wahyu dwi purnomo, S.Pd. dari hasil koordinasi tersebut, ketua pokdarwis kemudian menawarkan kerjasama kepada para anggota pokdarwis dan menyampaikan program kerja kkn untuk mendukung dan siap untuk berkerjasama dengan tim kkn.

3. Pembuatan Spot Foto di Area Jembatan Pelangi

Tim KKN berupaya untuk menindak lanjuti hasil kerja sama dengan Pordakwis Desa Watuaji. Hal ini terkait dengan adanya kegiatan pembuatan spot foto di area jembatan pelangi. Adanya pembuatan spot foto ini bertujuan untuk menarik minat para wisatan untuk berkunjung di Desa Watuaji untuk melihatkan pesona alam yang dikelilingi dengan sungai dan sawah di sekitar jembatan pelangi. Selain itu, menambah kecantikan alam yang bisa dimanfaatkan oleh semua orang.

4. Pengecatan Jembatan

Langkah selanjutnya tim KKN melanjutkan pengecatan di area jembatan pelangi dengan memberikan berbagai grafiti yang lucu dan unik serta lukisan menarik yang bisa dilihat oleh banyak orang. Keunikan grafiti yang dibuat ini memberikan dorongan khususnya kepada 
warga desa Watuaji agar lebih kreatif lagi bukan hanya soal wisata tetapi juga kreatif akan seni lukisan.

5. Sosialisasi master plan watu gebyok desa watuaji

Acara sosialisasi watu gebyok desa watuaji yang dilakukan tim pengabdian dilaksanakan pada tanggal 06 Maret 2021. Pemateri yang mengisi acara sosialisasi tersebut adalah Yayan Adi Saputro yang merupakan Dosen Teknik Sipil Unisnu Jepara. Dalam acara tersebut melibatkan kelompok sadar wisata Desa Watuaji, tokoh masyarakat dan segenap perangkat desa. Melalui acara tersebut diharapkan POKDARWIS dapat mengembangkan potensi wisata yang ada melalui pembuatan master plan sehingga pembangunan menjadi terstuktur dan terarah serta memperoleh hasil yang maksimal. Selanjutnya desa Watuaji siap untuk menjadi desa wisata.

6. Pembuatan master plan wisata watu gebyok desa watuaji

Pembuatan master plan ini bertujuan untuk mendapatkan gambaran umum rencana stategis pembangunan kedepannya, seta menjadi panduan pengembangan. Tidak bias dipungkiri bahwa pengembangan akan berdampak pada fasilitas publik dalam jangka waktu 10 hingga 20 tahun mendatang. Pembuatan master plan wisata watu gebyok desa watuaji bertujuan untuk menjadi acuan pembangunan wisata watu gebyok desa watuaji dan pengajuan dana proposal ke dinas pariwisata.

Rencana yang digunakan dalam pengabdian ini ialah menentukan lokasi wisata yang akan dikembangkan oleh anggota KKN dan pokdarwis desa Watuaji. Bentuk kegiatan pengembangan lokasi wisata diantaranya :

1. Lokasi area jembatan pelangi desa Watuaji

Jembatan pelangi merupakan jembatan penghubung antara Dukuh Pulerejo dengan Dukuh Brengkel, Tuaji, Bumiharjo dan Sendang.

2. Master Plan Wisata Watu Gebyok Desa Watuaji

Watu Gebyok adalah batu alam yang menyerupai dindin (tembok), konon katanya adalah cikal bakal terbentuknya Desa Watuaji. Hal ini menjadi potensi wisata didesa watuaji.

Dengan adanya program rencana pelaksanaan ini, tim KKN dan pokdarwis desa Watuaji akan mengangkat potensi desa secara bersama dengan melibatkan tim KKN UNISNU 2021 dan masyarakat yang bertujuan agar cepat terealisasi sesuai keinginan pemerintah desa.

Adapun secara lengkap alur proses pengabdian ini dapat dilihat di kerangka kerja pengabdian pada gambar 1 sebagai berikut :

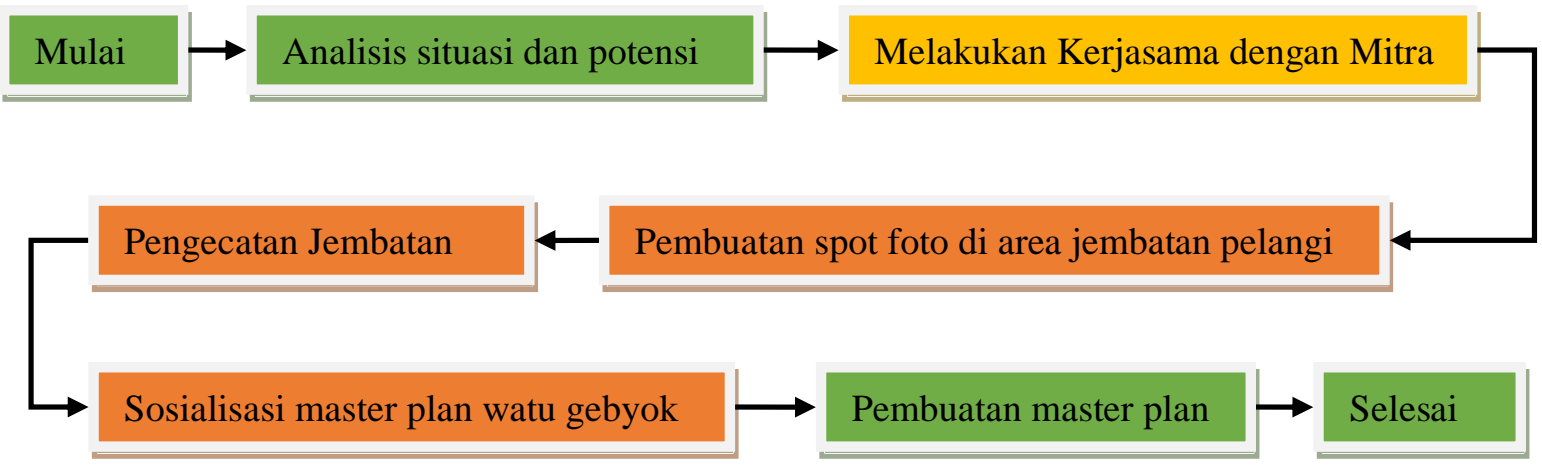

Gambar 1.Kerangka Kerja Kegiatan Pengabdian 
Selain kerangka kerja pengabdian mobilitas yang dibutuhkan tim pengabdian ini menjadi sesuatu yang penting untuk diperhatikan dalam menunjang keberhasilan yang telah ditentukan bersama. Adapun jarak yang ditempuh tim pengabdian ke tempat pengabdian seperti pada gambar 2.

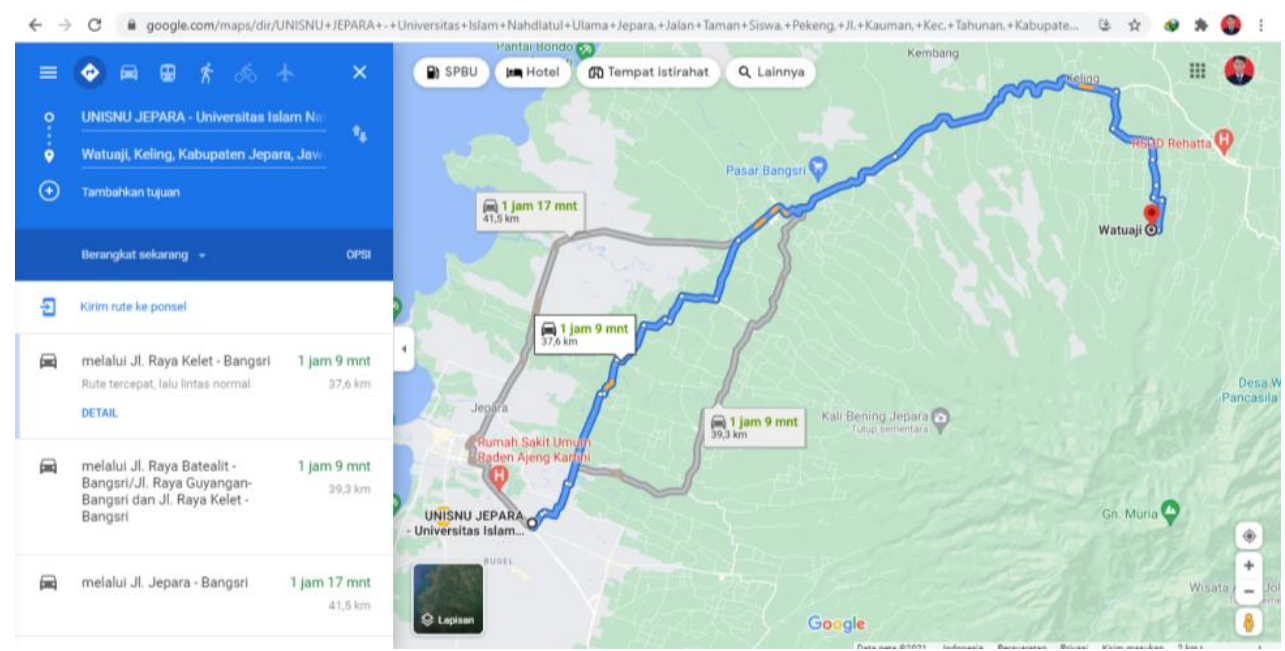

Gambar 2. Jarak Tempuh dari Perguruan Tinggi ke Lokasi

\section{HASIL PEMBAHASAN}

Dari hasil kegiatan yang dilakukan tim KKN Unisnu Jepara memberikan banyak sekali kegiatan di mitra baik kegiatan formal maupun non formal. Adapun rinciannya sebagai berikut :

1. Pembuatan Spot Foto di Area Jembatan Pelangi

Spot foto menjadi perbincangan yang menarik sebagai bahan untuk menarik para wisatawan. Hal ini juga diperlukan kreatifitas dalam proses pembuatannya. Tim KKN Unisnu mengadakan kegiatan ini guna untuk membantu mempromosikan Desa Watuaji yang sebenarnya memiliki pesona keindahan alam yang perlu diketahui oleh khalayak umum. Pembuatan spot foto ini dilakukan di area jembatan pelangi yang dikelilingi keindahan sawah dan sungai di area tersebut. kegiatan ini bertujuan menarik para wisatan untuk berkunjung serta membantu mempromosikan desa yang sebenarnya memiliki banyak wisata di dalamnya.

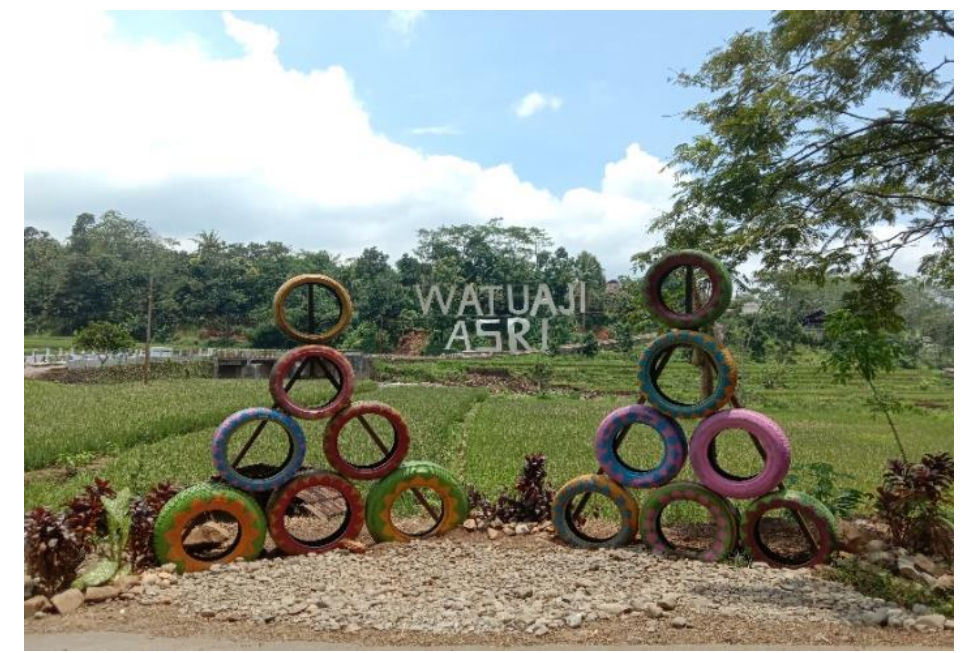

Gambar 3. Spot Foto Area Jembatan Pelangi 


\section{Pengecatan Jembatan}

Jembatan pelangi memiliki keindahan yang dikelilingi sungai dan sawah di sekitarnya. Melihat hal tersebut tim KKN berinisiatif melakukan pengecatan di area jembatan agar terlihat lebih indah dan menarik. Berbagai kegiatan yang dilakukan seperti adanya pembuatan grafiti dan lukisan yang menarik. Hal ini tentu menjadi tantangan bagi tim KKN agar bisa melakukan hal yang terbaik dan memberikan seni yang menarik untuk Desa Watuaji.

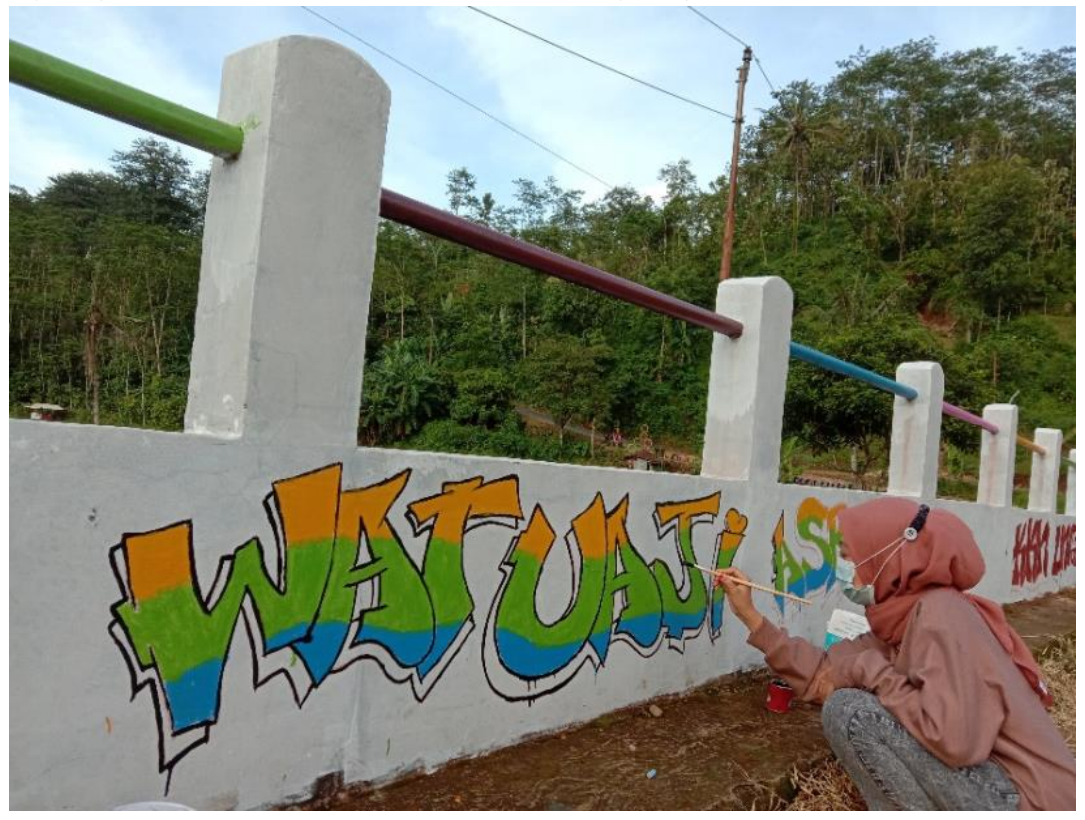

Gambar 4. Proses Pengecatan Jembatan

\section{Master Plan Wisata Watu Gebyok}

Adanya master plan memberikan gambaran kepada Pordakwis yang telah memberikan kepercayaan kepada tim KKN Unisnu Jepara. di dalam master plan ini memberikan gambaran mengenai letak lokasi wisata Watu Gebyok dengan adanya pembuatan cafe, berbagai aktifitas yang bisa dilakukan seperti kolam renang, pemancingan, out bond dan flying fox serta berbagai tempat religius yang bisa dimanfaatkan oleh para wisatan.

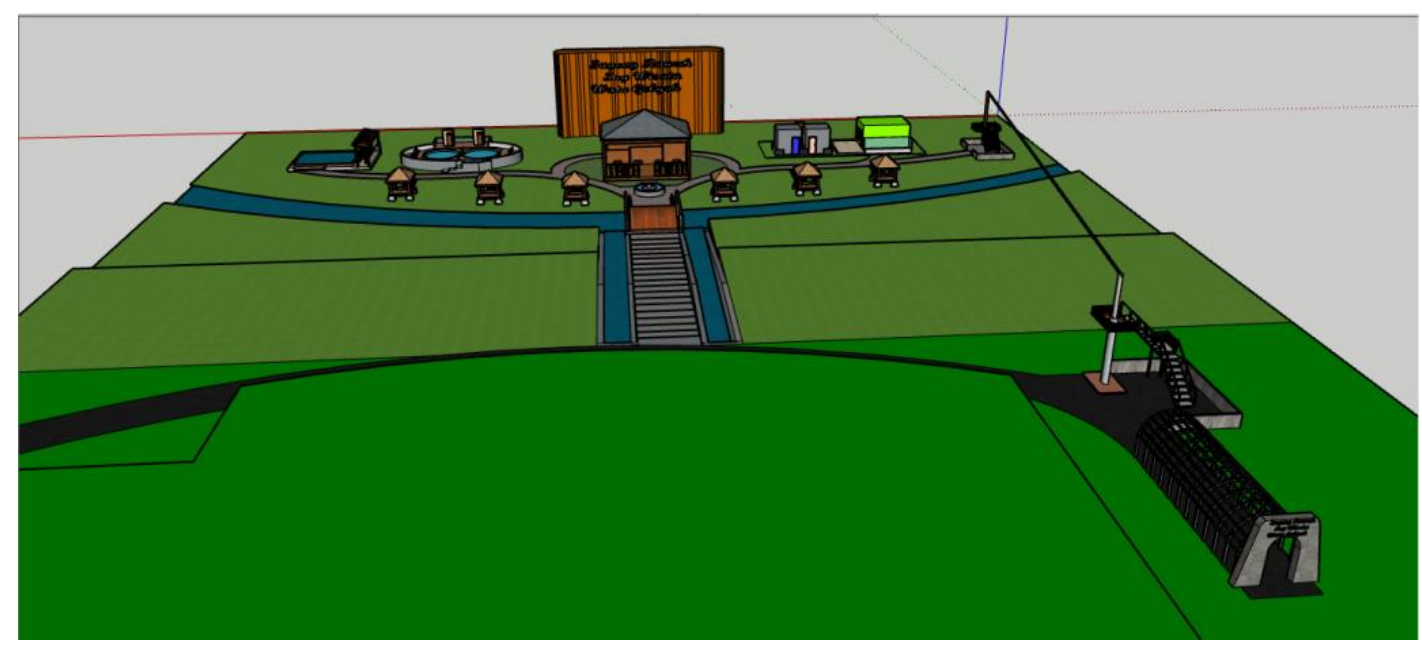

Gambar 5 Proses Pengecatan Jembatan 
4. Sosialisasi Master Plan

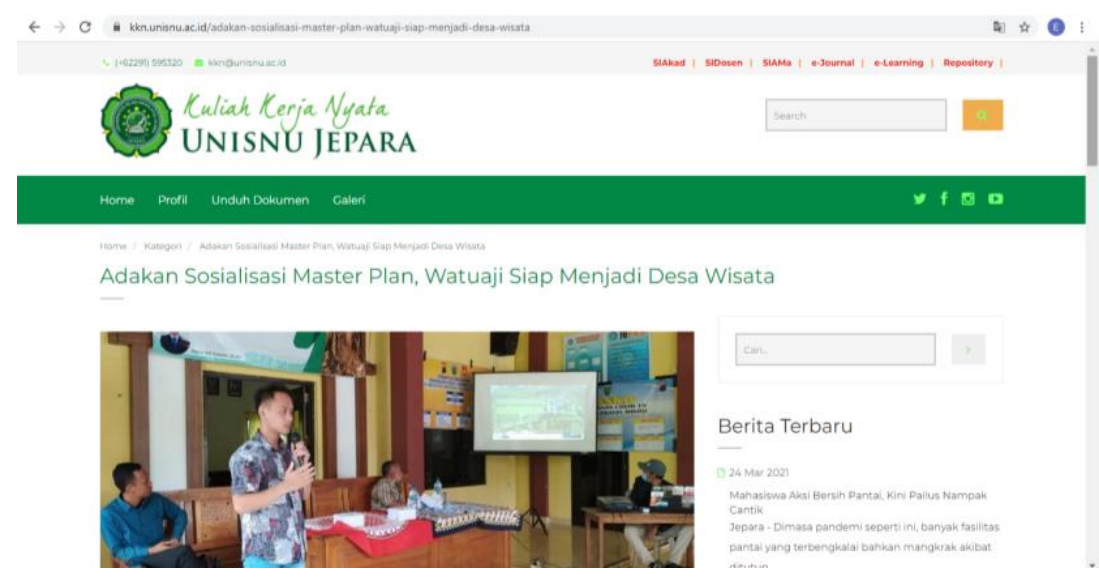

Gambar 5. Sosialisai master plan

Respon warga atas pengembangan desa wisata di desa watuaji ini memang sangat antusias, kemudian respon dari pemerintah desa adalah dengan memberikan alokasi dana untuk pengembangan dan peningkatan adanya wisata dengan cara memasukkan dalam pembahasan di MUSDES tahun depan. Adapun hasil dari tim pengabdian ini memberikan gambaran umum atas detail teknis untuk pengembangan sebagai pedoman pembangunan jangka pendek, menengah, dan jangka panjang.

\section{KESIMPULAN}

Sebagai hasil akhir laporan kemajuan pengabdian kepada masyarakat yang dilakukan oleh tim dosen Unisnu Jepara, maka dapat disimpulkan beberapa hal mengenai adanya kerja sama dengan PORDAKWIS dan petinggi desa Watuaji untuk mengadakan kegiatan sosialisasi master plan, pembuatan master plan, pembuatan spot foto area jembatan dan pengecatan jembatan pelangi. Kegiatan ini bertujuan agar dapat memberikan sebuah kenangan serta bentuk pengabdian tim KKN bagi masyarakat desa Watuaji. Ha ini terkait adanya penyelenggaraan sosialisasi master plan, karena pada dasarnya masyarakat watuaji masih belum begitu paham pembuatan master plan. Sehingga kami tim KKN berinisiatif membantu masyarakat dengan mengadakan sosialisasi ini untuk menambah wawasan serta pengetahuan dalam mengembangkan desa wisata agar mampu menjadi desa wisata yang unggul.

\section{DAFTAR PUSTAKA}

[1] K. Bangsri and K. Jepara, "Yayan Adi Saputro, 2) Muhammad Khoirul Mahfidh," vol. 4, no. 1, pp. 20-25, 2020.

[2] H. Out, M. Kuliah, C. Resort, S. Pengembangan, and D. A. N. Pengelolaan, "Konsep pengembangan kawasan desa wisata 1.," pp. 1-36, 2010.

[3] F. Zakaria and D. Suprihardjo, "Konsep Pengembangan Kawasan Desa Wisata di Desa Bandungan Kecamatan Pakong Kabupaten Pamekasan," Tek. Pomits, vol. 3, no. 2, pp. C245-C249, 2014, doi: 2337-3520.

[4] A. S. Sjamsu and I. M. K. A. Dharma, "Studi Kelayakan Potensi Pengembangan Desa Wisata di Kawasan Pulau Saponda Dalam Kabupaten Konawe," Semin. Nas. Teknol. Terap. Berbas. Kearifan Lokal, pp. 89-97, 2017, [Online]. Available: 
http://ojs.uho.ac.id/index.php/snt2bkl/article/download/5241/3904.

[5] R. Ardhiarini, "Identification of National Road Maintenance Needs Based on Strategic Plan of Directorate General Bina Marga (2015-2019)," J. Civ. Eng. Forum, vol. 2, no. 2, p. 187, 2017, doi: 10.22146/jcef.26583.

[6] Y. A. Saputro, "Detail enginering design," vol. 4, no. 2, pp. 116-122, 2021.

[7] C. E. Forum and U. G. Mada, "the Bogor Bus Station Relocation Impact Analysis To the Bogor Outer Ring Road (Borr) and Pangeran Sogiri Street Performance," J. Civ. Eng. Forum, vol. 21, no. 3, pp. 1291-1300, 2015, doi: 10.22146/jcef.18923. 